\title{
Role of CXC chemokine receptor type 4 as a lactoferrin receptor
}

\begin{tabular}{|r|l|}
\hline Journal: & Biochemistry and Cell Biology \\
\hline Manuscript ID & bcb-2016-0039.R2 \\
\hline Manuscript Type: & Article \\
\hline Date Submitted by the Author: & $28-$ Sep-2016 \\
\hline Complete List of Authors: & $\begin{array}{l}\text { Takayama, Yoshiharu; National Agriculture and Food Research } \\
\text { Organization, National Institute of Livestock and Grassland Science } \\
\text { Aoki, Reiji; National Agriculture and Food Research Organization, National } \\
\text { Institute of Livestock and Grassland Science } \\
\text { Uchida, Ryo; University of Tsukuba, Graduate School of Life and } \\
\text { Environmental Sciences; National Agriculture and Food Research } \\
\text { Organization, National Institute of Livestock and Grassland Science } \\
\text { Tajima, Atsushi; University of Tsukuba, Faculty of Life and Environmental } \\
\text { Sciences } \\
\text { Aoki-Yoshida, Ayako; The University of Tokyo, Graduate School of } \\
\text { Agricultural and Life Sciences; National Agriculture and Food Research } \\
\text { Organization, National Institute of Livestock and Grassland Sciences }\end{array}$ \\
\hline Keyword: & \begin{tabular}{l} 
CXCR4, SDF-1/CXCL12, Akt, dimerization, ubiquitination \\
\hline
\end{tabular} \\
\hline
\end{tabular}

\section{SCHOLARONE" \\ Manuscripts}




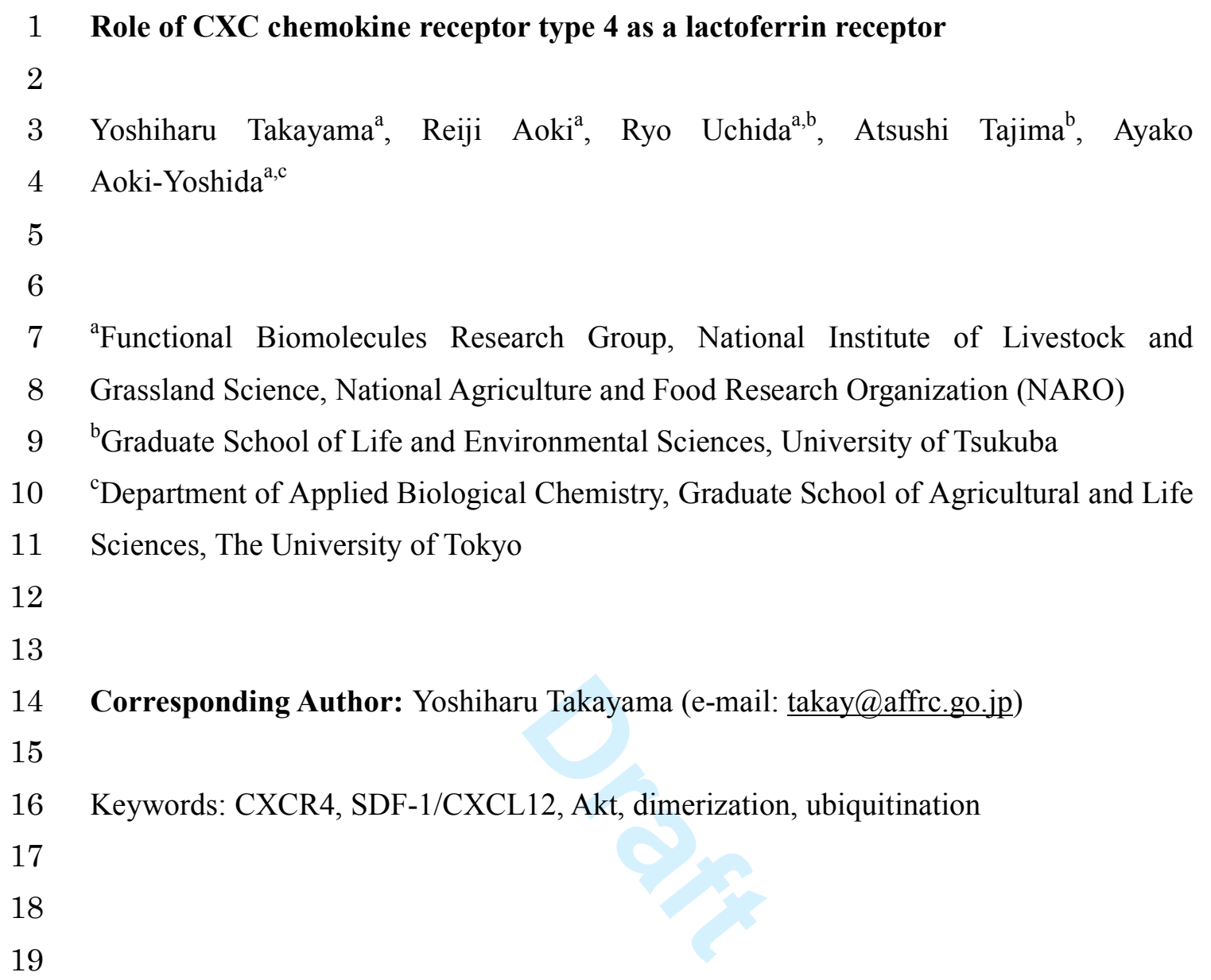




\section{Abstract}

2 Lactoferrin exerts its biological activities by interacting with receptors on target cells, 3 including LDL receptor-related protein-1 (LRP-1/CD91), intelectin-1 (Omentin-1), and 4 Toll-like receptor 4 (TLR4). However, the effects mediated by these receptors are not 5 sufficient to fully explain the many functions of lactoferrin. C-X-C-motif cytokine 6 receptor 4 (CXCR4) is a ubiquitously expressed G-protein coupled receptor for stromal 7 cell-derived factor-1 (SDF-1/CXCL12). Lactoferrin was found to be as capable as 8 SDF-1 in blocking infection by an HIV variant that uses CXCR4 as a co-receptor 9 (X4-tropic HIV), suggesting that lactoferrin interacts with CXCR4.

10 We addressed whether CXCR4 acts as a lactoferrin receptor using HaCaT human 11 keratinocytes and Caco-2 human intestinal cells. We found that bovine lactoferrin 12 interacted with CXCR4-containing lipoparticles, and that this interaction was not 13 antagonized by SDF-1. In addition, activation of Akt in response to lactoferrin was 14 abrogated by AMD3100, a small molecule inhibitor of CXCR4, or by a 15 CXCR4-neutralizing antibody, suggesting that CXCR4 functions as a lactoferrin 16 receptor able to mediate activation of the PI-3K/Akt signaling pathway. Lactoferrin 17 stimulation mimicked many aspects of SDF-1-induced CXCR4 activity, including 18 receptor dimerization, tyrosine phosphorylation, and ubiquitination. Cycloheximide 19 chase assays indicated that turnover of CXCR4 was accelerated in response to 20 lactoferrin. These results indicate that CXCR4 is a potent lactoferrin receptor that 21 mediates lactoferrin-induced activation of Akt signaling. 


\section{Introduction}

2 Lactoferrin is an iron-binding glycoprotein present in external secretions and secondary

3 granules of neutrophils. Lactoferrin contributes to host defense through its anti-bacterial

4 and immune modulatory activities (Legrand 2012; Alexander et al. 2012). In addition,

5 lactoferrin can regulate the growth and differentiation of many types of mammalian

6 cells (Alexander et al. 2012). The sulfated chain of cell surface proteoglycans is

7 regarded as the primary lactoferrin-binding site (Legrand et al. 2006). Following initial

8 binding, lactoferrin interacts with specific cell surface receptors and activates

9 intracellular signaling pathways, such as the ERK1/2 and PI3K/Akt signaling pathways.

10 The effect of lactoferrin binding depends on the types and distribution of receptors on

11 the cell surface (Suzuki et al. 2005).

12 Low-density lipoprotein receptor-related protein-1 (LRP-1, also known as CD91) is a

13 ubiquitously expressed receptor that belongs to the low-density lipoprotein (LDL)

14 receptor family (May et al. 2005). LRP-1 recognizes more than 40 different ligands,

15 including lactoferrin. LRP-1 participates in hepatocyte uptake and clearance of

16 lactoferrin from circulation (Willnow et al. 1992). In addition, LRP-1 is a potent

17 lactoferrin signaling receptor that converts lactoferrin binding to activation of the

18 ERK1/2 signaling pathway in fibroblasts, osteoblasts, keratinocytes, and adipocytes

19 (Takayama et al. 2003; Grey et al. 2004; Tang et al. 2010; Ikoma-Seki et al. 2015).

20 Intelectin-1 (Omentin-1) is a galactofuranose-binding lectin abundantly expressed in the

21 small intestine. Cell surface intelectin-1 participates in both the binding and endocytosis

22 of lactoferrin in a calcium-dependent manner (Suzuki et al. 2001). Lactoferrin-induced

23 activation of ERK1/2 is dependent on intelectin-1 (Jiang and Lönnerdal 2012). However,

24 studies using specific LRP-1 antagonists and RNA silencing of intelectin-1 suggest that

25 neither LRP-1 nor intelectin-1 are capable of mediating lactoferrin-induced Akt

26 activation (Grey et. al. 2006; Jiang and Lönnerdal 2012). Toll-like receptor 4 (TLR4) is

27 involved in lactoferrin-induced activation of the NF-kB signaling pathway (Ando et al.

28 2010). However, a lactoferrin receptor that is exclusively involved in Akt activation has 29 yet to be identified.

30 C-X-C-motif cytokine receptor 4 (CXCR4) is a C-X-C-type seven transmembrane

31 G-protein coupled receptor (GPCR). CXCR4 is expressed in a wide range of tissues,

32 including brain, heart, kidney, liver, lung, and spleen (Rossi and Zlotnik 2000; Wu and

33 Yoder 2009). The predominant ligand for CXCR4 is stromal cell-derived factor-1 
1 (SDF-1, also known as CXCL12). The SDF-1/CXCR4 axis is involved in a wide range 2 of physiological processes, such as embryonic development and stem cell motility 3 (Nagasawa 2014). CXCR4 activation in response to SDF-1 binding triggers the 4 activation of multiple signaling pathways, including PI-3K/Akt and ERK1/2 signaling 5 (Busillo and Benovic 2007; Wu and Yoder 2009).

6 In addition to its physiological function as a chemokine receptor for SDF-1, CXCR4 7 acts as a co-factor for HIV-1 and -2 viral entry into T-cells (Wu and Yoder 2009; 8 Arnolds and Spencer 2014). Infection of host cells by HIV-1 is triggered by binding of 9 the viral envelope glycoprotein gp120 to both the CD4 cell surface receptor and either 10 the CXCR4 or CCR5 chemokine receptor. In addition, CD4-independent association of 11 gp120 with CXCR4 has been reported (Hesselgesser et al. 1997). Interestingly, 12 lactoferrin was capable of blocking infection by an HIV variant that uses CXCR4 as a 13 co-receptor (X4-tropic HIV) (Berkhout et al. 2002; Berkhout et al. 2004; Saidi et al. 14 2006), and bovine lactoferrin interacts with the V3 loop of gp120 (Berkhout et al. 2002). 15 Bovine lactoferrin is protective against a broad spectrum of HIV strains that use 16 CXCR4 for infection, suggesting that bovine lactoferrin binds CXCR4 as effectively as 17 gp120 (Moriuchi and Moriuchi 2001).

18 In this study, we addressed whether CXCR4 acts as a lactoferrin receptor and found that 19 CXCR4-containing lipoparticles interacted with bovine lactoferrin. We tested the 20 involvement of CXCR4 in lactoferrin-induced Akt activation, and found that 21 lactoferrin-induced Akt activation was inhibited by AMD3100, a small molecule 22 CXCR4 antagonist, and by a CXCR4-neutralizing antibody. Lactoferrin stimulation 23 mimicked many aspects of CXCR4 activity induced by SDF-1 binding, including 24 dimerization, tyrosine phosphorylation, mono-ubiquitination, and ligand-induced 25 down-regulation. This study identifies CXCR4 as a potent lactoferrin receptor that 26 mediates lactoferrin-induced activation of Akt signaling.

\section{Materials and methods}

\section{Materials}

30 Bovine lactoferrin was obtained from Fonterra (Auckland, New Zealand). The iron 31 saturation of bovine lactoferrin was less than $30 \%,<20$ endotoxin units $(\mathrm{EU}) / \mathrm{mg}$, and $32>95 \%$ purity. HaCaT human immortalized keratinocytes were provided by Cell Lines 33 Service (Eppelheim, Germany). Caco-2 human intestinal epithelial cells were obtained 
1 from RIKEN Bioresource Center (Ibaraki, Japan). High-glucose (4.5 g/ml) Dulbecco's 2 Modified Eagle's Medium (DMEM), Eagle's Minimum Essential Medium (MEM), 3 non-essential amino acid solution (NEAA), protease inhibitor cocktail, and 4 cycloheximide were purchased from Sigma (St. Louis, MO, USA). Biotinylated 5 CXCR4 lipoparticles and control (null) lipoparticles were obtained from Integral 6 Molecular (Philadelphia, PA, USA). The lactoferrin ELISA quantitation kit was 7 purchased from Bethyl Laboratories (Montgomery, TX, USA). 8 3,3',5,5'-tetramethylbenzidine (TMB) chromogenic substrate, streptavidin conjugated 9 to horseradish peroxidase (HRP), and ELISA diluent solution were purchased from 10 eBioscience (San Diego, CA, USA). AMD3100 was obtained from Merck (Merck 11 Millipore, Darmstadt, Germany). LY294002 was obtained from Jena Bioscience (Jena, 12 Germany). MG132 was obtained from Enzo Life Sciences (Farmingdale, NY, USA). 13 Bis-sulfosuccinimidyl suberate (BS3), a protein crosslinker, and protein A/G agarose 14 were obtained from Pierce Biotechnology (Rockford, IL, USA). Anti-CXCR4 15 monoclonal antibody (clone 44708) and recombinant human SDF-1 were obtained from 16 R\&D Systems (Minneapolis, MN, USA). CXCR4-neutralizing antibody (clone 2F1) 17 was obtained from Abnova (Taipei, Taiwan). Anti-Akt (pan) antibodies, anti-phospho 18 Akt (Ser473) antibodies, and phospho p44/42 (Thr202/Tyr204) MAP kinase monoclonal 19 (E10) antibodies were obtained from Cell Signaling Technology (Danvers, MA, USA). 20 Anti-ubiquitin antibody (clone P4D1) was purchased from Santa Cruz Biotechnology 21 (Dallas, TX, USA). Anti-phosphotyrosine antibody (PY-20) was obtained from BD 22 Biosciences (San Jose, CA, USA). RIPA buffer was obtained from Nacalai Tesque 23 (Kyoto, Japan). Polyvinylidene difluoride (PVDF) membrane and enhanced 24 chemiluminescence prime Western blotting detection reagent were purchased from GE 25 Healthcare (Buckinghamshire, UK).

\section{ELISA binding assay}

28 Polystyrene wells were coated overnight with $100 \mu \mathrm{l}$ of sheep anti-bovine 29 lactoferrin antibody $(100 \mu \mathrm{g} / \mathrm{ml})$ in $50 \mathrm{mM}$ carbonate-bicarbonate $(\mathrm{pH} \mathrm{9.6)}$ at room 30 temperature. The wells were blocked with $200 \mu$ of TBS-T [50 mM Tris- $\mathrm{HCl}(\mathrm{pH} 8.0)$, $310.14 \mathrm{M} \mathrm{NaCl}$, and $0.05 \%$ Tween 20] containing $1 \%$ bovine serum albumin at $37^{\circ} \mathrm{C}$ for 1 32 hr. After washing five times with TBS-T, the coated plates were incubated with 10 $33 \mu \mathrm{g} / \mathrm{ml}$ bovine lactoferrin at room temperature for $1 \mathrm{hr}$. Biotinylated lipoparticles 
1 containing human CXCR4 were diluted with ELISA diluent solution at $4 \mu \mathrm{g} / \mathrm{ml}$, then 2 added to the wells and incubated at room temperature for $1 \mathrm{hr}$. Biotinylated null 3 lipoparticles (without a specific receptor) were used as reference samples to account for 4 any nonspecific binding. The wells were washed five times with TBS-T and incubated 5 for $1 \mathrm{hr}$ at room temperature with streptavidin-HRP at a dilution of 1:1,000 in TBS-T.

6 After five washes with TBS-T, TMB was added for development of color, and the 7 absorbance was read at $450 \mathrm{~nm}$.

\section{Cell culture}

10 HaCaT cells were maintained in high-glucose DMEM supplemented with $10 \%$ fetal 11 bovine serum (FBS), $100 \mathrm{U} / \mathrm{ml}$ penicillin, and $100 \mathrm{U} / \mathrm{ml}$ streptomycin in an atmosphere 12 of $5 \% \mathrm{CO}_{2}$ and $95 \%$ air at $37^{\circ} \mathrm{C}$. Caco-2 cells were maintained in MEM supplemented 13 with $10 \%$ FBS, 1\% NEAA, $100 \mathrm{U} / \mathrm{ml}$ penicillin, and $100 \mathrm{U} / \mathrm{ml}$ streptomycin in an 14 atmosphere of $5 \% \mathrm{CO}_{2}$ and $95 \%$ air at $37^{\circ} \mathrm{C}$.

\section{Cycloheximide chase assay}

17 HaCaT keratinocytes were treated with cycloheximide $(5 \mu \mathrm{g} / \mathrm{ml})$ for $15 \mathrm{~min}$, 18 followed by stimulation with bovine lactoferrin $(10 \mu \mathrm{M})$ or SDF-1 $(100 \mathrm{ng} / \mathrm{ml})$ for 3 or $196 \mathrm{hr}$. At each time point, cells were washed twice by ice-cold PBS and lysed in RIPA 20 buffer supplemented with $1 \%$ protease inhibitor cocktail.

\section{Crosslinking}

23 Serum-starved HaCaT keratinocytes $\left(10^{7}\right.$ cells $)$ were placed on ice and cooled by 24 the addition of ice-cold PBS. After three washes with ice-cold PBS, cells were 25 incubated with bovine lactoferrin $(10 \mu \mathrm{M})$ or SDF-1 $(100 \mathrm{ng} / \mathrm{ml})$ for $60 \mathrm{~min}$ at $4^{\circ} \mathrm{C}$. 26 After washing with ice-cold PBS, cells were treated with $1 \mathrm{mM}$ BS3 crosslinker for 30 27 min at $4^{\circ} \mathrm{C}$ with continuous rocking. The crosslinking reaction was terminated by the 28 addition of 0.02 volume of $1 \mathrm{M}$ Tris- $\mathrm{HCl}\left(\mathrm{pH} \mathrm{7.4)}\right.$ for $30 \mathrm{~min}$ at $4^{\circ} \mathrm{C}$. After washing 29 with ice-cold PBS, cells were lysed in RIPA buffer supplemented with $1 \%$ protease 30 inhibitor cocktail. Cell lysates were subjected to immunoprecipitation using 31 anti-CXCR4 antibody. 32

\section{Ubiquitination assay}


Serum-starved HaCaT keratinocytes were placed on ice and treated with MG132 $2(10 \mu \mathrm{M})$ for $6 \mathrm{hr}$. Cells were stimulated with bovine lactoferrin $(10 \mu \mathrm{M})$ or SDF-1 (100 $3 \mathrm{ng} / \mathrm{ml}$ ) for $30 \mathrm{~min}$ at $4^{\circ} \mathrm{C}$. After washing with ice-cold PBS, cells were lysed in RIPA 4 buffer supplemented with $1 \%$ protease inhibitor cocktail. Cell lysates were subjected to 5 immunoprecipitation using anti-CXCR4 antibody.

\section{Immunoprecipitation}

HaCaT cells were lysed in RIPA buffer supplemented with $1 \%$ protease inhibitor cocktail and centrifuged for $15 \mathrm{~min}$ at $15,000 \times \mathrm{g}$. Protein extract containing $400 \mu \mathrm{g}$ of protein was precleared by incubation with $20 \mu \mathrm{g}$ of Protein $\mathrm{A} / \mathrm{G}$ agarose for $60 \mathrm{~min}$. Precleared cell lysate was incubated with anti-CXCR4 antibody $(1 \mu \mathrm{g})$, followed by incubation with $20 \mu \mathrm{g}$ of Protein $\mathrm{A} / \mathrm{G}$ agarose for $60 \mathrm{~min}$. All incubation steps were carried out at $4{ }^{\circ} \mathrm{C}$ under gentle agitation. Protein $\mathrm{A} / \mathrm{G}$ agarose beads were washed four times with TNE buffer [20 mM Tris-HCl (pH 7.4), $0.15 \mathrm{M} \mathrm{NaCl}, 1 \%$ Nonidet P-40, 1 $\mathrm{mM}$ EDTA, and $5 \mathrm{mM}$ mercaptoethanol supplemented with $1 \%$ protease inhibitor cocktail]. Immunoprecipitated material was eluted by incubating the beads for $30 \mathrm{~min}$ at $37^{\circ} \mathrm{C}$ in Laemmli SDS-PAGE sample buffer.

\section{Western blotting}

Cells were harvested in RIPA buffer to yield cell lysates. To assess protein expression, cell lysates were resolved by $10 \%$ sodium dodecyl sulfate polyacrylamide gel electrophoresis and electrically transferred to a PVDF membrane. Subsequently, the membrane was treated with blocking reagent (Tris-buffered saline containing $0.1 \%$ Tween-20 and 5\% skim milk) for $2 \mathrm{hr}$ at room temperature. Blocked membranes were incubated with primary antibody, followed by incubation with HRP-conjugated secondary antibody. Immunoreactivity was detected using Western blotting detection 27 reagents.

\section{Data analysis}

Data are presented as means \pm standard deviation. Unpaired two-tailed t-test was applied to determine statistical significance $(\mathrm{p}<0.05)$ for each data set.

\section{Results}




\section{Interaction of lactoferrin with CXCR4}

2 We first assessed the ability of CXCR4 to bind bovine lactoferrin. When 3 CXCR4-containing lipoparticles and null lipoparticles (without a specific receptor) were 4 incubated with bovine lactoferrin immobilized to polystyrene wells, the binding of 5 CXCR4-containing lipoparticles was significantly higher (1.7-fold) than that of null 6 lipoparticles (Fig. 1). When CXCR4-containing and null lipoparticles were incubated 7 with uncoated polystyrene wells, only trace amounts of lipoparticles attached to the 8 wells. SDF-1 was previously reported to interact with the extracellular domain of 9 CXCR4 (Brelot et al. 2000). Therefore, we investigated the ability of SDF-1 to compete 10 with lactoferrin for interaction with CXCR4-containing lipoparticles. CXCR4 11 interaction with bovine lactoferrin was not inhibited by SDF-1 (100 ng/ml), suggesting 12 that bovine lactoferrin interacts with CXCR4 using a different mechanism than SDF-1.

\section{Role of CXCR4 on lactoferrin-induced Akt phosphorylation}

To determine whether CXCR4 is involved in lactoferrin-induced activation of intracellular signaling pathways, we assessed the effect of AMD3100, a small molecule inhibitor of CXCR4, on lactoferrin-induced Akt phosphorylation in Caco-2 human intestinal cells and HaCaT human keratinocytes. Treatment of serum-starved Caco-2 cells with SDF-1 $(100 \mathrm{ng} / \mathrm{ml})$ or bovine lactoferrin $(10 \mu \mathrm{M})$ led to Akt phosphorylation within $5 \mathrm{~min}$, and both SDF-1- and lactoferrin-induced Akt phosphorylation was inhibited by AMD3100 (Fig. 2a). In HaCaT keratinocytes, both SDF-1 and bovine lactoferrin induced Akt and ERK 1/2 phosphorylation. However, pretreatment with AMD3100 inhibited lactoferrin-induced Akt phosphorylation (Fig. 2b). The inhibitory effect of AMD3100 was comparable to that of LY294002, which downregulates Akt 25 phosphorylation. Interestingly, AMD3100 enhanced ERK1/2 phosphorylation in 26 lactoferrin treated HaCaT keratinocytes (Fig. 2b). To exclude any off-target effects of 27 AMD3100, we investigated the effects of a CXCR4-neutralizing antibody on 28 lactoferrin-induced Akt phosphorylation. As shown in Figure 2c, lactoferrin-induced 29 Akt phosphorylation was inhibited by pretreatment of HaCaT keratinocytes with 30 CXCR4-neutralizing antibody $(10 \mu \mathrm{g} / \mathrm{ml})$. These observations suggest that CXCR4 is 31 involved in lactoferrin-induced Akt phosphorylation in Caco-2 and HaCaT cells. 32

\section{Lactoferrin-induced dimerization of CXCR4}


As with other C-X-C-type chemokine receptors, ligand binding of CXCR4 results 2 in dimerization of the receptors (Vila-Coro et al. 1999; Busillo and Benovic 2007). 3 Therefore, we investigated whether bovine lactoferrin triggers the dimerization of 4 CXCR4 in HaCaT keratinocytes. BS3-mediated crosslinking was performed in 5 keratinocytes stimulated with bovine lactoferrin $(10 \mu \mathrm{M})$. Immunoprecipitation with an 6 anti-CXCR4 antibody (clone 44708) followed by Western blotting using anti-CXCR4 7 antibody (clone 2F1) revealed an $80 \mathrm{kDa}$ band in cells stimulated with bovine 8 lactoferrin (Fig. 3a). The size of this band was close to the expected molecular weight 9 of a CXCR4 dimer, suggesting that binding of bovine lactoferrin triggers dimerization 10 of CXCR4.

\section{Lactoferrin-induced tyrosine phosphorylation of CXCR4}

13 The SDF-1/CXCR4 interaction stimulates tyrosine phosphorylation of CXCR4, 14 followed by the activation of the JAK/STAT pathway (Vila-Coro et al. 1999; Busillo 15 and Benovic 2007). To evaluate the effect of bovine lactoferrin on tyrosine 16 phosphorylation of CXCR4, serum-starved HaCaT keratinocytes were stimulated with 17 bovine lactoferrin $(10 \mu \mathrm{M})$ for $5 \mathrm{~min}$. HaCaT keratinocytes were also stimulated with 18 SDF-1 (100 ng/ml) as a positive control. Immunoprecipitation of cell lysates with an 19 anti-CXCR4 antibody followed by Western blotting with an anti-phosphotyrosine 20 antibody showed a rapid increase in CXCR4 tyrosine phosphorylation that peaked at 2 $21 \mathrm{~min}$ and then decreased (Fig. 3b). Tyrosine-phosphorylated proteins of a similar 22 molecular weight $(40 \mathrm{kDa})$ were observed in $\mathrm{HaCaT}$ cells treated with bovine 23 lactoferrin within $5 \mathrm{~min}$, suggesting that lactoferrin induces CXCR4 tyrosine 24 phosphorylation.

\section{Lactoferrin-induced ubiquitination of CXCR4}

27 Upon stimulation by SDF-1, CXCR4 is mono-ubiquitinated, and this modification 28 acts as an endosomal sorting signal that marks the receptor for lysosomal degradation 29 (Marchese and Benovic 2001; Busillo and Benovic 2007). Therefore, we examined the 30 effect of bovine lactoferrin on ubiquitination of CXCR4. HaCaT keratinocytes were 31 treated with bovine lactoferrin $(10 \mu \mathrm{M})$ or SDF-1 $(100 \mathrm{ng} / \mathrm{ml})$ for $30 \mathrm{~min}$ in the 32 presence of the proteasome inhibitor MG132. Ubiquitination of CXCR4 was detected 33 by immunoprecipitation with an anti-CXCR4 antibody followed by Western blotting 
1 with an anti-ubiquitin antibody. As shown in Figure 3c, CXCR4 underwent 2 ubiquitination in response to treatment with bovine lactoferrin or SDF-1. The extent of 3 lactoferrin-induced ubiquitination was comparable to that of SDF-1-induced 4 ubiquitination.

5

\section{Lactoferrin-induced down-regulation of CXCR4}

whether endogeneous CXCR4 undergoes degradation in response to bovine lactoferrin

11 stimulation. In the absence of an agonist, a modest reduction in immunoreactive

12 CXCR4 was observed in cycloheximide-treated HaCaT keratinocytes. In the presence

13 of bovine lactoferrin $(10 \mu \mathrm{M})$ or SDF-1 (100 ng/ml), CXCR4 underwent significant

14 degradation following 3 or $6 \mathrm{hr}$ of agonist treatment (Fig. 4).

\section{Discussion}

17 Previous studies show that lactoferrin inhibits X4-tropic HIV infection by inhibiting 18 attachment of the viral envelope protein gp120 to CXCR4 on the surface of target cells 19 (Berkhout et al. 2002; Berkhout et al. 2004; Saidi et al. 2006). Therefore, we speculated 20 that CXCR4 behaves as a lactoferrin receptor. Here, we present evidence of a novel role 21 for CXCR4 as a receptor for lactoferrin that mediates lactoferrin-induced Akt activation. 22 The best characterized receptor for lactoferrin-induced cell signaling is LRP-1 (Suzuki 23 et al. 2005). However, lactoferrin-induced Akt activation is not inhibited by receptor 24 associated protein (RAP), which inhibits ligand interactions with LRP, suggesting that 25 LRP-1 is not responsible for lactoferrin-induced Akt activation (Grey et al. 2006). In 26 Caco-2 human intestinal cells, intelectin-1 is responsible for lactoferrin uptake and 27 activation of ERK1/2 signaling in response to lactoferrin (Jiang et al. 2011). 28 Nevertheless, lactoferrin-induced activation of Akt was not inhibited by RNA silencing 29 of intelectin-1 (Jiang and Lönnerdal 2012). Therefore, a receptor other than LRP-1 or 30 intelectin-1 must be responsible for lactoferrin-induced Akt activation.

31 Lactoferrin-induced Akt activation was inhibited by a CXCR4 antagonist (AMD3100) 32 or a CXCR4-neutralizing antibody (Fig. 2b, 2c and 5), suggesting that CXCR4 plays an 33 important role in lactoferrin-induced Akt activation. However, unlike in HaCaT 
1 keratinocytes and Caco-2 intestinal cells, lactoferrin-induced Akt activation was not 2 inhibited by treatment with a CXCR4 antagonist in normal human dermal fibroblasts 3 (data not shown), indicating that the role of CXCR4 in Akt activation is cell-type 4 specific, and suggesting the involvement of a different receptor in lactoferrin-induced 5 Akt activation in dermal fibroblasts.

6 CXCR4 is an evolutionarily conserved protein (Rossi and Zlotnik 2000). CXCR4 7 expression is heterogeneous among different cells of the leukocyte lineage, suggesting 8 that CXCR4 may act as a lactoferrin receptor in cells other than keratinocytes and 9 intestinal cells. The promoting effect of lactoferrin on CXCR4 expression is reported in 10 dendritic cells (Spadaro et al. 2008). In addition to Akt activation, CXCR4 is also 11 involved in STAT3 activation (Vila-Coro et al. 1999). Further study is required to 12 explore the role of CXCR4 as an lactoferrin receptor.

13 We found that lactoferrin increased tyrosine phosphorylation and dimerization of 14 CXCR4 (Fig. 3). Homo-dimerization of CXCR4 is an initial step for the activation of 15 the JAK/STAT pathway (Busillo and Benovic 2007). In addition, tyrosine 16 phosphorylation of CXCR4 correlated with the activation of the JAK/STAT pathway 17 (Vila-Coro et al. 1999; Busillo and Benovic 2007), implying that lactoferrin activates 18 the JAK/STAT pathway by a CXCR4-dependent mechanism.

19 It was reported that ERK1/2 is downstream of CXCR4, and that SDF-1 triggers ERK1/2 20 activation via a CXCR4-dependent mechanism (Busillo and Benovic 2007, Wu and 21 Yoder 2009). However, we found that a CXCR4 antagonist (AMD3100) increased 22 ERK1/2 phosphorylation in lactoferrin-treated HaCaT keratinocytes (Fig. 2b), 23 suggesting that lactoferrin-induced ERK1/2 phosphorylation is mediated by another 24 receptor and lactoferrin inhibits ERK1/2 phosphorylation as a result of CXCR4 binding. 25 Therefore, the functional outcome of CXCR4 activation is likely determined by the 26 specifics of ligand-CXCR4 interaction.

27 Nevertheless, lactoferrin mimicked many aspects of CXCR4 activity induced by SDF-1 28 binding, including receptor dimerization, tyrosine phosphorylation, and 29 mono-ubiquitination (Fig. 3). Ubiquitination of CXCR4 is a common way of mediating 30 internalization and degradation of CXCR4 by the lysosomal pathway (Busillo and 31 Benovic 2007). In addition, tyrosine phosphorylation of CXCR4 drives endocytic 32 internalization of CXCR4 (Busillo and Benovic 2007). We observed that lactoferrin 33 treatment accelerated the downregulation of CXCR4 to the same extent as SDF-1 (Fig. 
1 4), suggesting that lactoferrin promotes the CXCR4 degradation by increasing tyrosine 2 phosphorylation and mono-ubiquitination of CXCR4.

3 The mechanism through which SDF-1 induces the endocytosis and degradation of 4 CXCR4 is not fully understood. A region in the extracellular N-terminal domain of 5 CXCR4 is responsible for the initial binding of SDF-1, and this is followed by its 6 interaction with extracellular loops and the membrane-spanning domains of CXCR4 7 (Brelot et al. 2000). This second interaction is required for the activation of intracellular 8 signaling. HIV-1 infection via CXCR4 seems to be dependent on interaction of SDF-1 9 with the residues of CXCR4 involved in activation of intracellular signaling (Brelot et 10 al. 2000). It will be valuable to characterize the lactoferrin-binding site of CXCR4 and 11 assess its binding properties.

12 In this study, we found that the amount of CXCR4-containing lipoparticles 13 bound by lactoferrin was 1.7 times the number of null lipoparticles bound 14 (Fig. 1), suggesting that bovine lactoferrin interacts with the extracellular domain of 15 CXCR4. At the surface of mammalian cells, the sulfated chain of the proteoglycan is the 16 main lactoferrin-binding site and occupies approximately $80 \%$ of the total binding 17 (Legrand et al. 2006). Lactoferrin bound to null lipoparticles may represent the binding 18 of lactoferrin to heparan sulfate proteoglycans (HSPGs).

19 SDF-1 blocks CXCR4-dependent HIV-1 infection in T-lymphocytes (Bleul et al. 1996; 20 Oberlin et al. 1996; Valenzuela-Fernández et al. 2001). This inhibitory effect of SDF-1 21 is due not only to competitive interaction of SDF-1 and gp120 with CXCR4, but also to 22 the down-regulation of CXCR4 at the cell surface by induction of CXCR4 endocytosis 23 (Amara et al. 1997). We found here that lactoferrin also enhanced CXCR4 24 down-regulation by enhancing CXCR4 turnover (Fig. 4). This lactoferrin-induced 25 CXCR4 down-regulation implies that lactoferrin might inhibit HIV infection of target 26 cells by accelerating CXCR4 endocytosis.

\section{References}

30 Alexander, D.B., Iigo, M., Yamauchi, K., Suzui, M., and Tsuda, H. 2012. Lactoferrin: an 31 alternative view of its role in human biological fluids. Biochem. Cell Biol. 32 90(3):279-306. 
1 Amara, A., Gall, S.L., Schwartz, O., Salamero, J., Montes, M., Loetscher, P., Baggiolini, 2 M., Virelizier, J.L., and Arenzana-Seisdedos, F. 1997. HIV coreceptor downregulation 3 as antiviralprinciple: SDF-1alpha-dependent internalization of the chemokine receptor 4 CXCR4 contributes to inhibition of HIV replication. J. Exp. Med. 186(1):139-146.

6 Ando, K., Hasegawa, K., Shindo, K., Furusawa, T., Fujino, T., Kikugawa, K., Nakano, 7 H., Takeuchi, O., Akira, S., Akiyama, T., Gohda, J., Inoue, J., and Hayakawa, M. 2010. 8 Human lactoferrin activates NF-kappaB through the Toll-like receptor 4 pathway while 9 it interferes with the lipopolysaccharide-stimulated TLR4 signaling. FEBS J. $10 \quad$ 277(9):2051-2066.

Arnolds, K.L., and Spencer, J.V. 2014. CXCR4: a virus's best friend? Infect. Genet. 13 Evol. 25:146-156.

Berkhout, B., van Wamel, J.L., Beljaars. L., Meijer, D.K., Visser, S., and Floris, R. 16 2002. Characterization of the anti-HIV effects of native lactoferrin and other milk proteins and protein-derived peptides. Antiviral Res. 55(2):341-355.

Berkhout, B., Floris, R., Recio, I., and Visser, S. 2004. The antiviral activity of the milk protein lactoferrin against the human immunodeficiency virus type 1. Biometals. 17(3):291-294.

Bleul, C.C., Farzan,M., Choe, H., Parolin, C., Clark-Lewis, I., Sodroski, J., and Springer, T.A. 1996. The lymphocyte chemoattractant SDF-1 is a ligand for LESTR/fusin and blocks HIV-1entry. Nature. 382(6594):829-833.

Brelot, A., Heveker, N., Montes, M., and Alizon, M. 2000. Identification of residues of 28 CXCR4 critical for human immunodeficiency virus coreceptor and chemokine receptor 29 activities. J. Biol. Chem. 275(31):23736-23744.

30

31 Busillo, J.M., and Benovic, J.L. 2007. Regulation of CXCR4 signaling. Biochim. 32 Biophys. Acta. 1768(4):952-963. 
1 Grey, A., Banovic, T., Zhu, Q., Watson, M., Callon, K., Palmano, K., Ross, J., Naot, D.,

2 Reid, I.R., and Cornish, J. 2004. The low-density lipoprotein receptor-related protein 1

3 is a mitogenic receptor for lactoferrin in osteoblastic cells. Mol. Endocrinol.

4 18(9):2268-2278.

5

6 Grey, A., Zhu, Q., Watson, M., Callon, K., and Cornish, J. 2006. Lactoferrin potently

7 inhibits osteoblast apoptosis, via an LRP1-independent pathway. Mol. Cell Endocrinol.

$8 \quad 251(1-2): 96-102$.

10 Hesselgesser, J., Halks-Miller, M., DelVecchio, V., Peiper, S.C., Hoxie, J., Kolson, 11 D.L., Taub, D., and Horuk, R. 1997. CD4-independent association between HIV-1 12 gp120 and CXCR4: functional chemokine receptors are expressed in human neurons. 13 Curr. Biol. 7(2):112-121.

Ikoma-Seki, K., Nakamura, K., Morishita, S., Ono, T., Sugiyama, K., Nishino, H., 16 Hirano, H., and Murakoshi, M. 2015. Role of LRP1 and ERK and cAMP Signaling 17 Pathways in Lactoferrin-Induced Lipolysis in Mature Rat Adipocytes. PLoS One. 18 10(10):e0141378.

Jiang, R., Lopez, V., Kelleher, S.L., and Lönnerdal B. 2011. Apo- and holo-lactoferrin are both internalized by lactoferrin receptor via clathrin-mediated endocytosis but differentially affect ERK-signaling and cell proliferation in Caco-2 cells. J. Cell Physiol. 226(11):3022-3031.

Jiang, R., and Lönnerdal, B. 2012. Apo- and holo-lactoferrin stimulate proliferation of 26 mouse crypt cells but through different cellular signaling pathways. Int. J. Biochem. 27 Cell Biol. 44(1):91-100.

29 Legrand, D., Elass, E., Carpentier, M., and Mazurier, J. 2006. Interactions of lactoferrin 30 with cells involved in immune function. Biochem. Cell Biol. 84(3):282-290.

32 Legrand, D. 2012. Lactoferrin, a key molecule in immune and inflammatory processes. 33 Biochem. Cell Biol. 90(3):252-268. 
1

2 Marchese, A., and Benovic, J.L. 2001. Agonist-promoted ubiquitination of the G 3 protein-coupled receptor CXCR4 mediates lysosomal sorting. J Biol Chem. 4 276(49):45509-45512.

5

6 May, P., Herz, J., and Bock, H.H. 2005. Molecular mechanisms of lipoprotein receptor 7 signalling. Cell Mol. Life Sci. 62(19-20):2325-2338.

8

32 Spadaro, M., Caorsi ,C, Ceruti, P., Varadhachary, A., Forni, G., Pericle, F., Giovarelli, 33 M. 2008. Lactoferrin, a major defense protein of innate immunity, is a novel maturation 
1 factor for human dendritic cells. FASEB J. 22(8):2747-2757.

2

3 Suzuki, Y.A., Shin, K., and Lönnerdal, B. 2001. Molecular cloning and functional 4 expression of a human intestinal lactoferrin receptor. Biochemistry. $5 \quad 40(51): 15771-15779$.

7 Suzuki, Y.A., Lopez, V., and Lönnerdal, B. 2005. Mammalian lactoferrin receptors:

8 structure and function. Cell Mol. Life Sci. 62(22):2560-2575.

Takayama, Y., Takahashi, H., Mizumachi, K., and Takezawa, T. 2003. Low density 11 lipoprotein receptor-related protein (LRP) is required for lactoferrin-enhanced collagen 12 gel contractile activity of human fibroblasts. J. Biol. Chem. 278(24):22112-22118. and Li, J. 2010. Human lactoferrin stimulates skin keratinocyte function and wound re-epithelialization. Br. J. Dermatol. 163(1):38-47.

Valenzuela-Fernández, A., Palanche, T., Amara, A., Magerus, A., Altmeyer, R., 19 Delaunay, T., Virelizier, J.L., Baleux, F., Galzi, J.L., and Arenzana-Seisdedos, F. 2001. 20 Optimal inhibition of X4 HIV isolates by the CXC chemokine stromal cell-derived 21 factor 1 alpha requires interaction with cell surface heparan sulfate proteoglycans. J. 22 Biol. Chem. 276(28):26550-26558.

24 Vila-Coro, A.J., Rodríguez-Frade, J.M., Martín De Ana, A., Moreno-Ortíz, M.C., 25 Martínez-A, C., and Mellado, M. 1999. The chemokine SDF-1alpha triggers CXCR4 26 receptor dimerization and activates the JAK/STAT pathway. FASEB J. 27 13(13):1699-1710.

29 Willnow, T.E., Goldstein, J.L., Orth, K., Brown, M.S., and Herz, J. 1992. Low density 30 lipoprotein receptor-related protein and gp330 bind similar ligands, including 31 plasminogen activator-inhibitor complexes and lactoferrin, an inhibitor of chylomicron 32 remnant clearance. J. Biol. Chem. 267(36):26172-26180. 
1 Wu, Y., and Yoder, A. 2009. Chemokine coreceptor signaling in HIV-1 infection and 2 pathogenesis. PLoS Pathog. 5(12):e1000520.

\section{Acknowledgments}

This work was supported by the Cross-ministerial Strategic Innovation Promotion Program (SIP), "Technologies for creating next-generation agriculture,

8 forestry and fisheries" (ID: 14532924), from the Council for Science, Technology and

9 Innovation (CSTI) (YT, RA, and AA), a Grant-in-Aid for Scientific Research C (no.

10 25450413) from the Japan Society for the Promotion of Science (YT), and a Grant from 11 the Morinaga Foundation for Health and Nutrition (YT).

\section{Figure legends}

15 Figure 1. Binding of CXCR4-containing lipoparticles to immobilized bovine 16 lactoferrin. Biotinylated lipoparticles containing CXCR4 and null lipoparticles 17 (without a specific receptor) were incubated with bovine lactoferrin immobilized to 18 polystyrene wells. Uncoated polystyrene wells served as negative controls. Binding of 19 biotinylated lipoparticles was detected by incubation with horseradish 20 peroxidase-labeled streptavidin, followed by a tetramethylbenzidine (TMB) peroxidase 21 substrate. Absorbance measured at $450 \mathrm{~nm}$ was used to assess lipoparticle binding to 22 bovine lactoferrin. For the competition assay, CXCR4-containing lipoparticles were 23 incubated with bovine lactoferrin in the presence of $100 \mathrm{ng} / \mathrm{ml} \mathrm{SDF}-1$. Data are 24 presented as the mean \pm standard deviation. $* * *, \mathrm{p}<0.001$; NS, no significant 25 difference.

Figure 2. Involvement of CXCR4 in lactoferrin-induced Akt phosphorylation. (a)

28 Effect of a CXCR4 antagonist on lactoferrin-induced Akt phosphorylation in Caco-2 29 human intestinal cells. Serum-starved cells were stimulated with bovine lactoferrin (10 $30 \mu \mathrm{M})$ or SDF-1 $(100 \mathrm{ng} / \mathrm{ml})$ in the presence or absence of AMD3100, a CXCR4 31 antagonist, for $5 \mathrm{~min}$. Akt phosphorylation was assessed by Western blotting. (b) Effect 32 of a CXCR4 antagonist on lactoferrin-induced Akt and ERK1/2 phosphorylation in 33 HaCaT human keratinocytes. Serum-starved cells were stimulated with bovine 
1 lactoferrin $(10 \mu \mathrm{M})$ in the presence or absence of AMD3100 $(10 \mu \mathrm{M})$ or LY294002 (20

$2 \mu \mathrm{M}$ ) for 5 min. Akt and ERK1/2 phosphorylation were assessed by Western blotting. (c)

3 Effect of a CXCR4-neutralizing antibody on lactoferrin-induced Akt phosphorylation.

4 Serum-starved HaCaT keratinocytes were pretreated with CXCR4-neutralizing antibody

$5 \quad$ (CXCR4 Ab: $10 \mu \mathrm{g} / \mathrm{ml}$ ) for $30 \mathrm{~min}$, followed by stimulation with bovine lactoferrin (10

$6 \mu \mathrm{M}$ ) for 5 min. Akt phosphorylation was assessed by Western blotting. Western blotting

7 using an anti-pan Akt antibody was performed to confirm equal loading. Band intensity

8 was measured with Image J 1.50i software and normalized against Akt, and the protein

9 levels are shown at the bottom of each blot.

10

11 Figure 3. Modification of CXCR4 by bovine lactoferrin. (a) Lactoferrin-induced 12 dimerization of CXCR4. Serum-starved HaCaT keratinocytes were cooled on ice and 13 stimulated with bovine lactoferrin $(10 \mu \mathrm{M})$ or SDF-1 $(100 \mathrm{ng} / \mathrm{ml})$ at $4^{\circ} \mathrm{C}$ for $60 \mathrm{~min}$. 14 Cell surface proteins were crosslinked with a membrane impermeable crosslinker (BS3) 15 for $30 \mathrm{~min}$ at $4^{\circ} \mathrm{C}$. Cell lysates were subjected to immunoprecipitation with an 16 anti-CXCR4 antibody (clone 44708), followed by Western blotting using anti-CXCR4 17 antibody (clone 2F1). (b) Lactoferrin-induced tyrosine phosphorylation of CXCR4. 18 HaCaT keratinocytes were stimulated with bovine lactoferrin $(10 \mu \mathrm{M})$ or SDF-1 (100 $19 \mathrm{ng} / \mathrm{ml}$ ) for $5 \mathrm{~min}$ at $37^{\circ} \mathrm{C}$. Tyrosine phosphorylation of CXCR4 was detected by 20 immunoprecipitation with anti-CXCR4 antibody (clone 44708) followed by Western 21 blotting with an anti-phosphotyrosine antibody (PY20). (c) Lactoferrin-induced 22 mono-ubiquitination of CXCR4. HaCaT keratinocytes were treated with MG132 (10 $23 \mu \mathrm{M})$ for $6 \mathrm{hr}$, followed by stimulation with bovine lactoferrin $(10 \mu \mathrm{M})$ or SDF-1 (100 $24 \mathrm{ng} / \mathrm{ml}$ ) for $5 \mathrm{~min}$. Cell lysates were subjected to immunoprecipitation with an 25 anti-CXCR4 antibody (clone 44708), followed by Western blotting with an 26 anti-ubiquitin antibody (clone P4D1). Band intensity was measured with ImageJ 1.50i 27 software and normalized against CXCR4 in the immunoprecipitate, and the protein 28 levels are shown at the bottom of each blot.

30 Figure 4. Lactoferrin-induced degradation of CXCR4. HaCaT keratinocytes were 31 treated with cycloheximide $(5 \mu \mathrm{g} / \mathrm{ml})$ for $15 \mathrm{~min}$, followed by stimulation with bovine 32 lactoferrin $(10 \mu \mathrm{M})$ or SDF-1 $(100 \mathrm{ng} / \mathrm{ml})$ for the indicated times. The reduction in 33 CXCR4 was detected by Western blotting with an anti-CXCR4 antibody (clone 2F1). 
1 Western blotting using an anti-GAPDH antibody was performed to confirm equal 2 loading. Band intensity was measured with ImageJ $1.50 \mathrm{i}$ software and normalized 3 against GAPDH, and the protein levels are shown at the bottom of each blot.

4

5 Figure 5. Diagram illustrating CXCR4 as lactoferrin receptor that activates the 6 PI-3K/Akt signaling pathway. Bovine lactoferrin (BLF)-induced activation of the 7 PI-3K/Akt signaling pathway was inhibited by AMD3100, a CXCR4 inhibitor, 8 suggesting that BLF activates the pathway by a CXCR4-dependent mechanism. Both 9 BLF and stromal derived factor-1 (SDF-1) were bound to CXCR4 in a non-competitive 10 manner and the specifics of binding resulted in activation of non-identical signaling 11 pathways. 


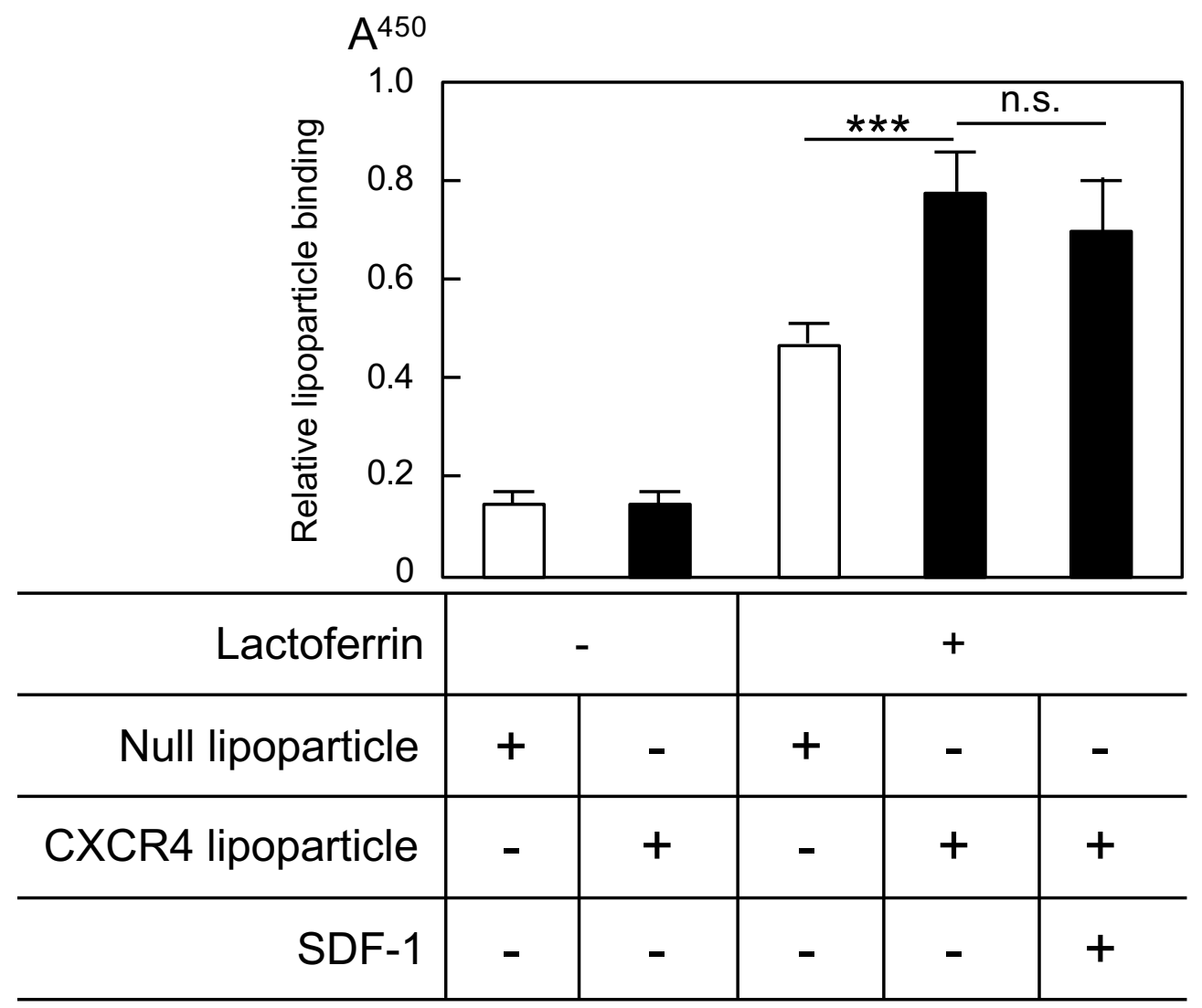

Fig.1 Takayama et al. https://mc06.manuscriptcentral.com/bcb-pubs 
A

\begin{tabular}{c|c|c|c|c|c|c}
\hline AMD3100 & \multicolumn{3}{|c|}{-} & \multicolumn{3}{|c}{+} \\
\hline Lactoferrin & - & - & + & - & - & + \\
\hline SDF-1 & - & + & - & - & + & - \\
\hline
\end{tabular}

P-Akt

$\begin{array}{llllll}42 & 78 & 100 & 24 & 15 & 35\end{array}$

Akt

B

\begin{tabular}{c|c|c|c|c|c|c}
\hline Lactoferrin & \multicolumn{3}{|c|}{-} & \multicolumn{3}{c}{+} \\
\hline AMD3100 & - & + & - & - & + & - \\
\hline LY294002 & - & - & + & - & - & + \\
\hline
\end{tabular}

P-Akt

$\begin{array}{llllll}18 & 11 & 6 & 100 & 56 & 40\end{array}$

Akt

P-ERK1/2

$\begin{array}{llllll}3 & 4 & 0 & 100 & 174 & 77\end{array}$

C

\begin{tabular}{c|c|c|c|c}
\hline Lactoferrin & \multicolumn{2}{|c|}{-} & \multicolumn{2}{c}{+} \\
\hline CXCR4 Ab & - & + & - & + \\
\hline P-Akt & & & & - \\
& 1 & 1 & 100 & 45 \\
Akt & & &
\end{tabular}

Fig.2 Takayama et al. ${ }_{\text {https://mc06.manuscriptcentral.com/bcb-pubs }}$ 
A

\begin{tabular}{c|c|c|c}
\hline SDF-1 & - & + & - \\
\hline Lactoferrin & - & - & + \\
\hline
\end{tabular}

124

90

43

32
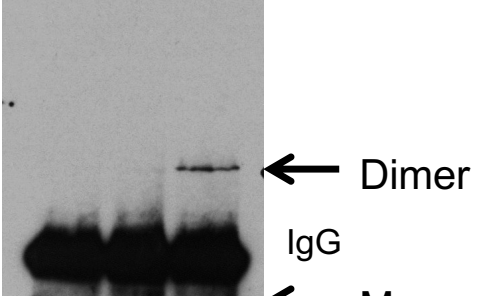

$\lg G$

$\leftarrow$ Monomer

(2)

02100

B
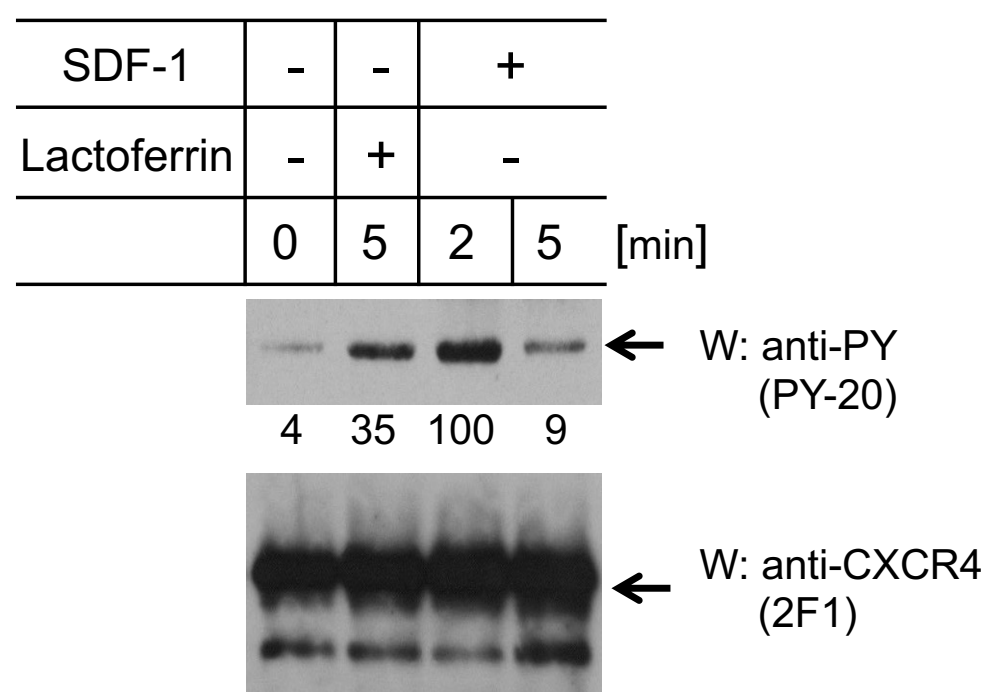

C

IP: anti-CXCR4 (\#44708)

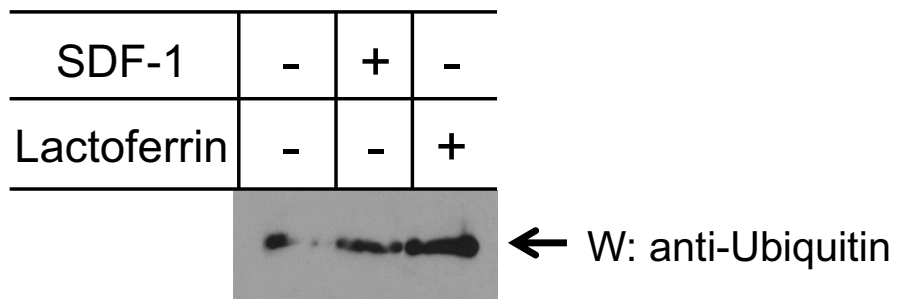

$13 \quad 45 \quad 100$

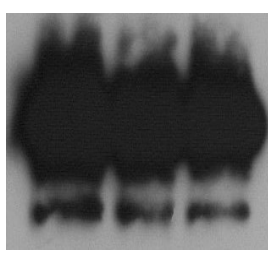

$\leftarrow$ W: anti-CXCR4

(2F1)

IP: anti-CXCR4(\#44708)

Fig.3 Takayama et al. ${ }_{\text {https://mc06.manuscriptcentral.com/bcb-pubs }}$ 


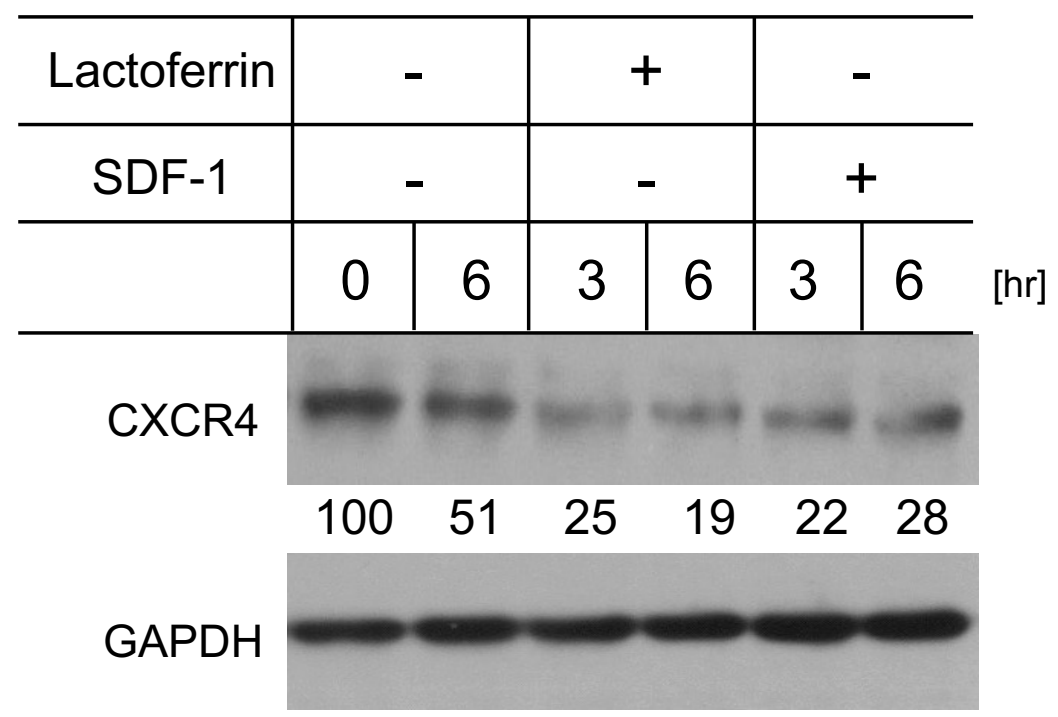

Fig.4 Takayama et al. https://mc06.manuscriptcentral.com/bcb-pubs 


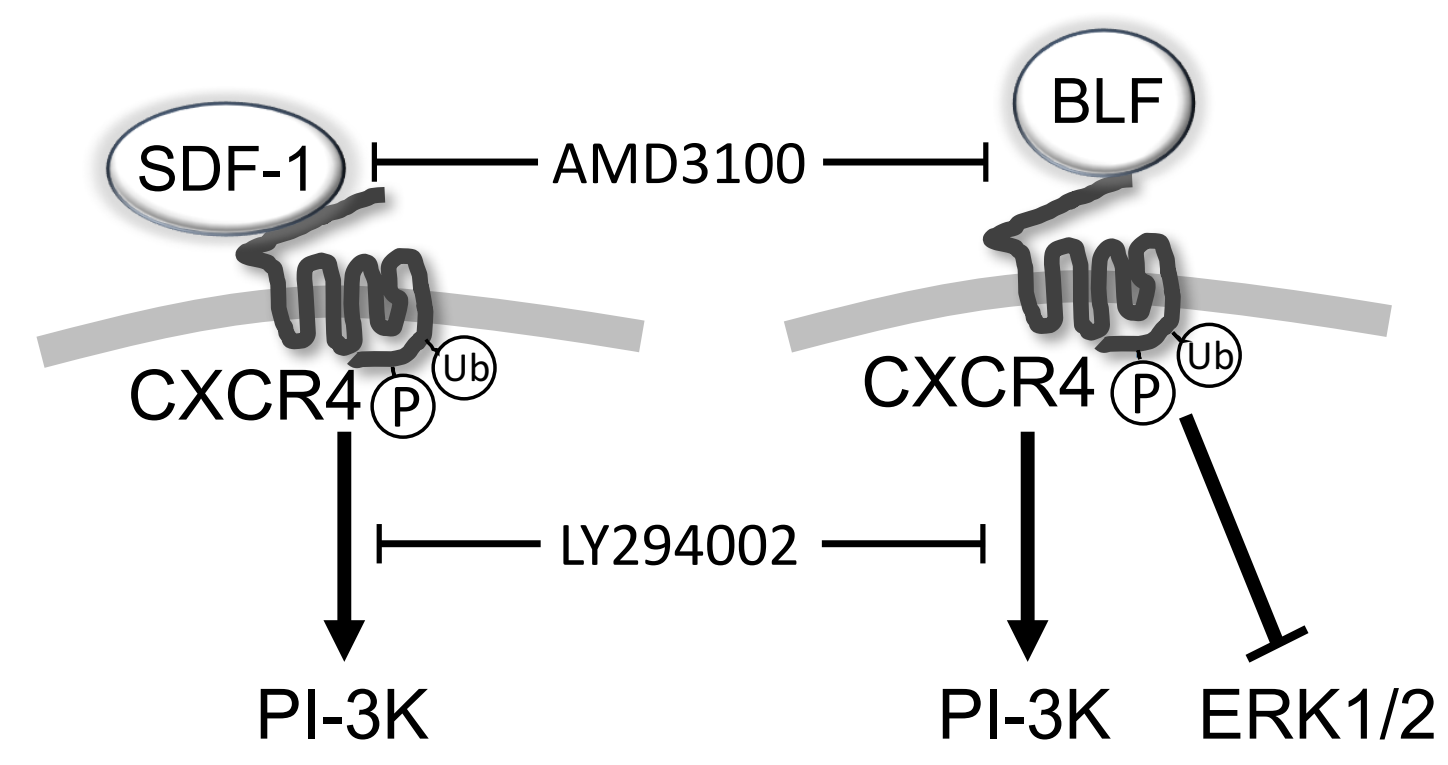

Fig.5 Takayama et al., 